\title{
GEOSYNTHETIC REINFORCED SLOPES: LIMIT EQUILIBRIUM AND FINITE ELEMENT ANALYSES
}

\author{
KA-ChING SAN ${ }^{\mathrm{i})}$, Dov LeShCHINSKY ${ }^{\mathrm{ii})}$ and TAMOtSU MATSUI ${ }^{\mathrm{iii}}$
}

\begin{abstract}
This note presents a comparative study of geosynthetic reinforced slope analyses. The comparison is between predictions of a finite element (FE) method and a limit equilibrium (LE) method. The comparisons are limited to the potential failure surface and the maximum tensile force developed in the geosynthetic reinforcement layers. These two items signify the design output in the LE analysis of geosynthetic reinforced slopes. The agreement between EE and LE methods is found to be reasonably good in terms of both location of critical slip surfaces and required strength of reinforcement.
\end{abstract}

Key words: failure, finite element method, safety factor, stability analysis, strain, slope stability (IGC: E0/E13)

\section{INTRODUCTION}

Finite element (FE) slope stability method, using strain-based failure judgment method, has been proposed by Matsui and San (1993). Its applicability to practical problems has been demonstrated through two Class-A predictions (Matsui and San, 1992a and 1992c). This note compares the predictions of this FE method with the results of a rigorous limit equilibrium (LE) analysis.

Many factors could affect the results of stability analysis using FE and some have been discussed elsewhere (San, Matsui and Katsuraya, 1990). However, in the Class-A Denver Wall prediction, it has been demonstrated that accurate failure prediction of geosynthetic reinforced walls could be successfully achieved by using proper modeling of the various components comprising the problem and material properties (Matsui and San, 1992c).

In this note, comparisons between FE and LE reinforced slope stability analyses are conducted. First, reinforced slopes with dense and loose backfills, for three slope inclinations, are analyzed by the LE analysis. Then, FE analysis of the reinforced slopes, designed by the LE analysis, is performed utilizing the Duncan and Chang (1970) model. The backfill material properties correspond to data from triaxial tests, but the coefficient of earth pressure at-rest is chosen so that the $L E$ result of one arbitrary slope inclination will fit the FE result. Finally, using the same parameters, FE analysis for other slopes is performed and compared with the LE analysis.

\section{LIMIT EQUILIBRIUM ANALYSIS}

The design problem to be considered is a $5 \mathrm{~m}$ high granular slope with ten equally spaced horizontal reinforcement layers, as shown in Fig. 1. The overall safety factor, $F_{s}$, is 1.0. Two types of backfills are considered, dense backfill with $c=0.0$ and $\phi=35^{\circ}$, and loose backfill

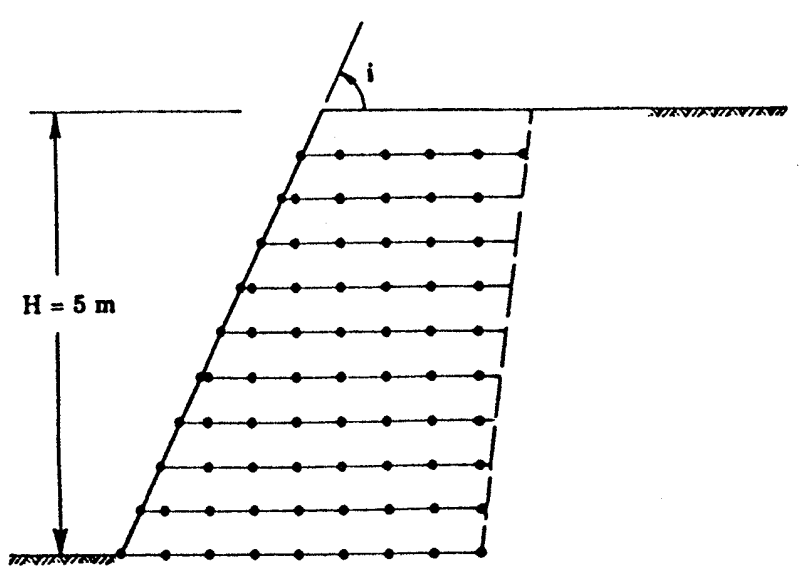

Fig. 1. The slope to be considered

i) Chief Research Enegineer, Geotop Corporation, and Research Fellow, Depertment of Civil Engineering, Osaka University. (Previously, Visiting Assistant Professor, University of Delaware, Newark, Delaware, USA.)

ii) Professor, Department of Civil Engineering, University of Delaware, Newark, Delaware 19716, USA.

iii) Professor, Department of Civil Engineering, Osaka University, Osaka. Manuscript was received for review on July 6, 1993.

Written discussions on this paper should be submitted before October 1, 1994 to the Japanese Society of Soil Mechanics and Foundation Engineering, Sugayama Bldg. 4 F, Kanda Awaji-cho 2-23, Chiyoda-ku, Tokyo 101, Japan. Upon request the closing date may be extended one month. 
having a trace of cohesion with $c=3.0 \mathrm{kPa}$ and $\phi=20^{\circ}$. For both backfills $\gamma=20 \mathrm{kN} / \mathrm{m}^{3}$. The soil-geosynthetic interaction coefficients are $C_{i}=0.8$ and $C_{d s}=1.0$. Note that $C_{i}$ represents the ratio between Coulomb's shear strength of the interface of reinforcement-backfill and the shear strength of backfill; its value is typically determined from pullout test (Leshchinsky, 1992). $C_{d s}$ is the direct sliding coefficient and it represents a similar relationship as $C_{i}$; however, its value is established based on a direct shear test, presumably simulating the sliding of soil block over the reinforcement layer (Leshchinsky, 1992).

Three slope inclinations were studied (i equals $75^{\circ}, 60^{\circ}$ and $45^{\circ}$ ). The analysis was conducted using 'STRATASLOPE,' a LE slope stability analysis computer code (Leshchinsky, 1992). In this procedure, the reinforcement strength is determined based on internal stability considerations; reinforcement length is determined based on possible compound failure and direct sliding of the reinforced mass.

In assessing the internal stability, log spiral slip surfaces, passing through all reinforcing layers, are examined; the one rendering the maximum required reinforcement strength is considered the critical surface. Leshchinsky and Lambert (1991) have demonstrated the adequacy of $\log$ spirals to represent critical slip surfaces in reinforced slopes. Furthermore, they have shown that the maximum height of a stable slope based on the log spiral limit equilibrium analysis procedure is very close to the measured value (i.e., the required reinforcement ultimate tensile strength from the log spiral analysis is close to the one measured at failure). Their observations, however, were limited to internal failure mode.

Compound failure analysis used by Leshchinsky (1992) considers log spiral surface (i.e., a rotational failure) emerging at the toe and extending through the reinforced soil and into the retained soil. In fact, the length of each reinforcing layer is extended so that the most critical log spiral passing at its end will produce the same prescribed factor of safety; deeper slip surfaces will yield safety factors exceeding the prescribed value (Leshchinsky, 1992). In other words, the log spiral failure mechanism was assumed to prevail also for possible compound failure passing through the end of each reinforcing layer. In fact, these surfaces determine the required length of each layer down to the second layer from the bottom. Since the compound surfaces are assumed to emerge at the toe, the required length of bottom layer cannot be determined by these surfaces (i.e., they all intersect this layer at the same point, the toe). Bottom layer, however, should be anchored long enough to provide adequate pullout resistance. Consequently, there are $(n-1)$ such surfaces ( $n=$ number of reinforcing layers), each yielding the same safety factor. In Figs. 2 through 7 the outer-most compound surfaces (i.e., log spiral for second reinforcement layer from bottom) are plotted.

Direct sliding analysis considers a two-wedge mechanism in which one wedge is sliding directly over the bottom reinforcement layer. This sliding is due to the lateral pressure exerted by the second wedge that is located in the unreinforced zone. The inclination of the interwedge force resultant was taken equal to the internal angle of friction. This force equilibrium analysis results in the required length to prevent such sliding.

Referring to Fig. 1, reinforcement length at the bottom is selected based on the direct sliding or compound failure (whichever is longer); top reinforcement length is based on maximum length obtained from compound failure analysis. Length of intermediate layers is adjusted according to top and bottom layers. This practical layout results in overall reinforcement length that is somewhat longer than necessary based on compound failure. Hence, it assures that the safety factor against compound failure (i.e., the most frequent type of failure) actually exceeds the prescribed value.

\section{FINITE ELEMENT ANALYSIS}

The use of finite element method to analyze the stability of geotechnical problems needs an appropriate definition of failure. Definitions of failure commonly used in practice are mainly based on stress failure criterion. However, it appears that failure of a soil structure is more reasonably defined as a state of rapid increase of strains. Consequently, a strain-based failure judgment method for finite element stability analysis has been proposed by Matsui and San (1993). In the FE analysis, failure is defined as the development of a full failure shear strain zone in the soil. The failure shear strain zone is the potential failure pattern in which the shear strain exceeds a cutoff value (Matsui and San, 1990 and 1992b). The failure shear strain of soil (i.e., the cutoff value) can be obtained from the standard triaxial test.

In the present analysis, the dense backfill is assumed as hyperbolic stress-strain elastic materials (Duncan and Chang, 1970) with $\phi=35^{\circ}$ and failure shear strain of $4 \%$. The loose backfill possesses a trace of cohesion of $c=3.0$ $\mathrm{kPa}$, and $\phi=20^{\circ}$ and failure shear strain of $15 \%$. The hyperbolic stress-strain parameters for the dense backfill are assumed as: $K=2000, K_{u r}=2120, n=0.54$, and $R_{f}=0.91$. The hyperbolic stress-strain parameters for the loose backfill are assumed as: $K=295, K_{u r}=1090$, $n=0.65$, and $R_{f}=0.90$. The failure shear strains and the hyperbolic stress-strain parameters correspond to data from triaxial tests on the dense and loose silica sand (Duncan and Chang, 1970). For both backfills $\gamma=20 \mathrm{kN} / \mathrm{m}^{3}$. The reinforcement is assumed as geosynthetic having $E=2.73 \times 10^{5} \mathrm{kN} / \mathrm{m}$ and $A=7.50 \times 10^{-4} \mathrm{~m}^{2} / \mathrm{m}$. The interface between the soil and reinforcement is modeled by an elastoplastic joint element (Matsui and San, 1989).

The critical lengths of the reinforcement obtained from $L E$ analysis for a safety factor of one are used as an input in the FE analysis. The finite element analysis of the reinforced slope was performed by adding elements from the bottom to the top of the slope, and applying the gravity force to each element. The $K_{0}=\sigma_{h} / \sigma_{v}$ value was used to specify the initial stresses of the added elements. In the FE analysis of the $60^{\circ}$ slopes, for both dense and loose backfills, the value of $K_{0}$ was gradually reduced in 
subsequent runs from its empirical value $\left(K_{0}=1-\sin \phi\right)$ until the failure of the slope occurred using the strainbased failure judgment method. It should be noted that the empirical value $\left(K_{0}=1-\sin \phi\right)$ may not always satisfy the initial boundary stress conditions. The empirical values $\left(K_{0}=1-\sin \phi\right)$ of the dense and loose backfills are 0.43 and 0.66 , respectively. It was found the values of $K_{0}$ at failure for the dense and loose backfill walls are 0.40 and 0.62 , respectively. Using these values of $K_{0}$, analyses of $75^{\circ}$ and $45^{\circ}$ slopes for both dense and loose backfills were conducted. The maximum reinforcement tensile force and the failure pattern of the reinforced slopes were then compared with the results obtained from LE analysis.

\section{COMPARISONS}

Figures 2 to 7 show the patterns of shear strain for the $75^{\circ}, 60^{\circ}$ and $45^{\circ}$ reinforced slopes for both dense and loose backfills obtained from the FE. The failure surfaces, both critical and compound, obtained from the $\mathrm{LE}$ analysis are also plotted on these figures. It can be seen that the failure patterns obtained from FE compare well with those obtained from LE. Generally, it appears that the LE traces of the compound failure surfaces are not likely locations for the development of slip surfaces as would be predicted by the FE; i.e., the critical spirals corresponding to internal stability are more likely locations. As previously noted, the plotted compound surfaces are the outer-most ones and the reinforcement length is specified based on the maximum obtained from both compound and direct sliding analyses. Consequently, there is reinforcement in excess of length needed based on the prescribed safety factor in the compound analysis. Hence, the plotted compound surface does not signify a critical LE situation when the practical layout is specified and analyzed by the FE. However, plotting this surface, superimposed on the FE results, is instructive in realizing the effects the practical design layout (Fig. 1) has on what is considered in a simplified analysis the potential compound failure.

The required reinforcement strengths from $\mathrm{FE}$ are quite close to those from LE as shown in Tables 1 and 2.

Table 1. Required reinforcement strength $(\mathrm{kN} / \mathrm{m})$ (dense granular backfill)

\begin{tabular}{c|c|c|c}
\hline$i$ & Finite element method & STRATASLOPE & Difference \\
\hline $75^{\circ}$ & 9.0 & 8.0 & 1.0 \\
$60^{\circ}$ & 6.0 & 5.0 & 1.0 \\
$45^{\circ}$ & 3.0 & 2.0 & 1.0 \\
\hline
\end{tabular}

Table 2. Required reinforcement strength $(\mathrm{kN} / \mathrm{m})$ (loose backfill)

\begin{tabular}{c|c|c|c}
\hline$i$ & Finite element method & STRATASLOPE & Difference \\
\hline $75^{\circ}$ & 17.0 & 15.0 & 2.0 \\
$60^{\circ}$ & 10.0 & 11.0 & 1.0 \\
$45^{\circ}$ & 9.0 & 7.0 & 2.0 \\
\hline
\end{tabular}

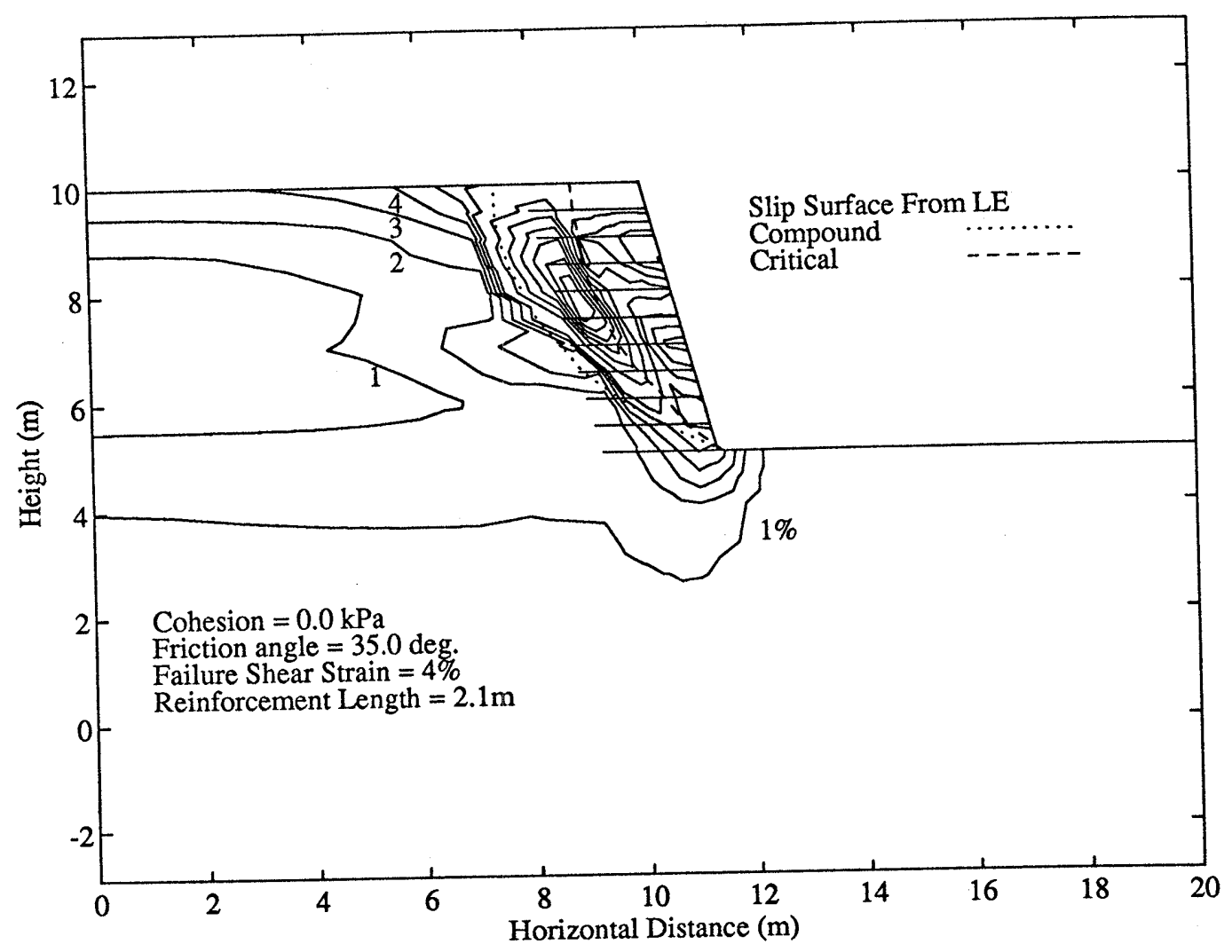

Fig. 2. Failure pattern for $75^{\circ}$ slope (dense granular backfill) 


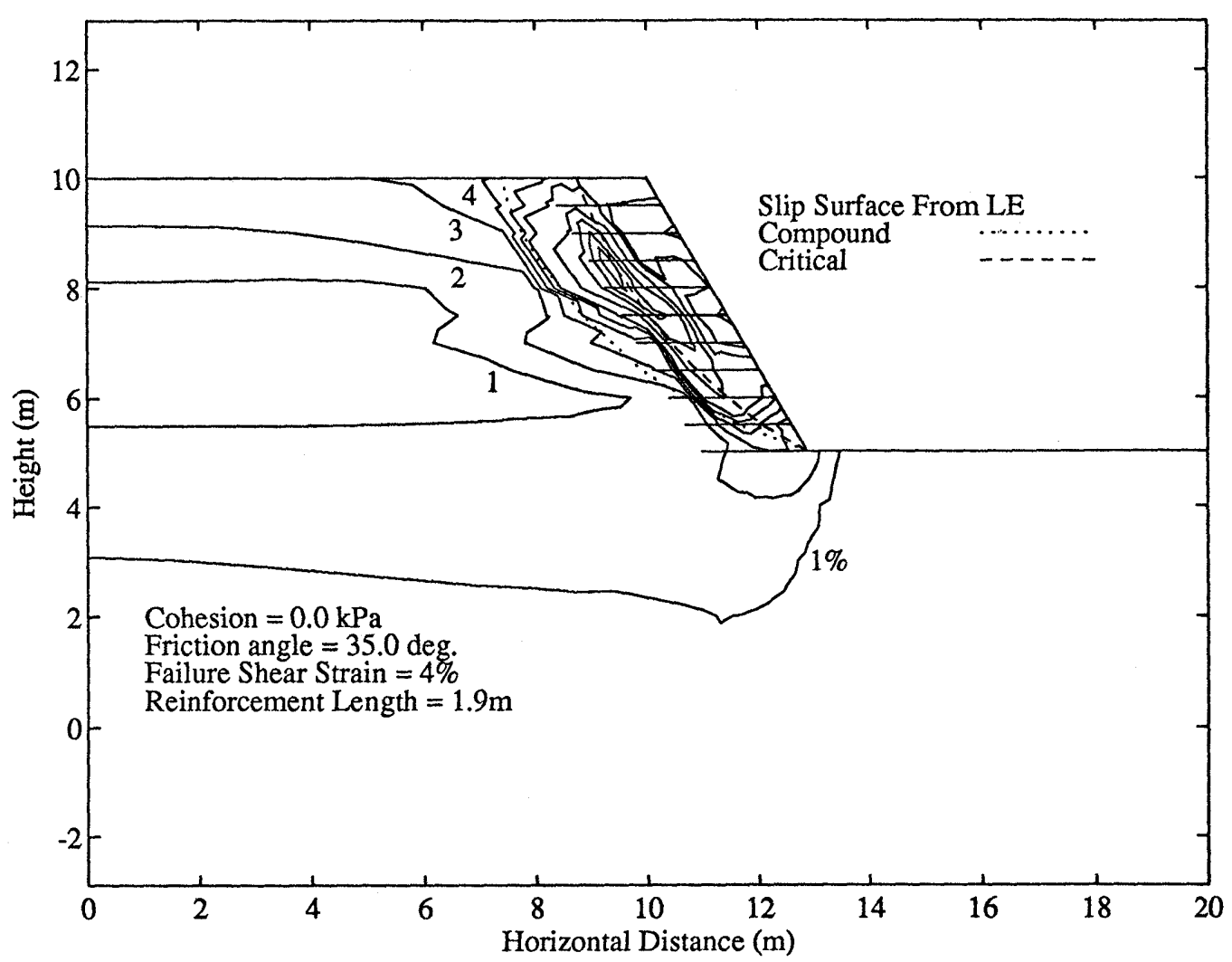

Fig. 3. Failure pattern for $60^{\circ}$ slope (dense granular backfill)

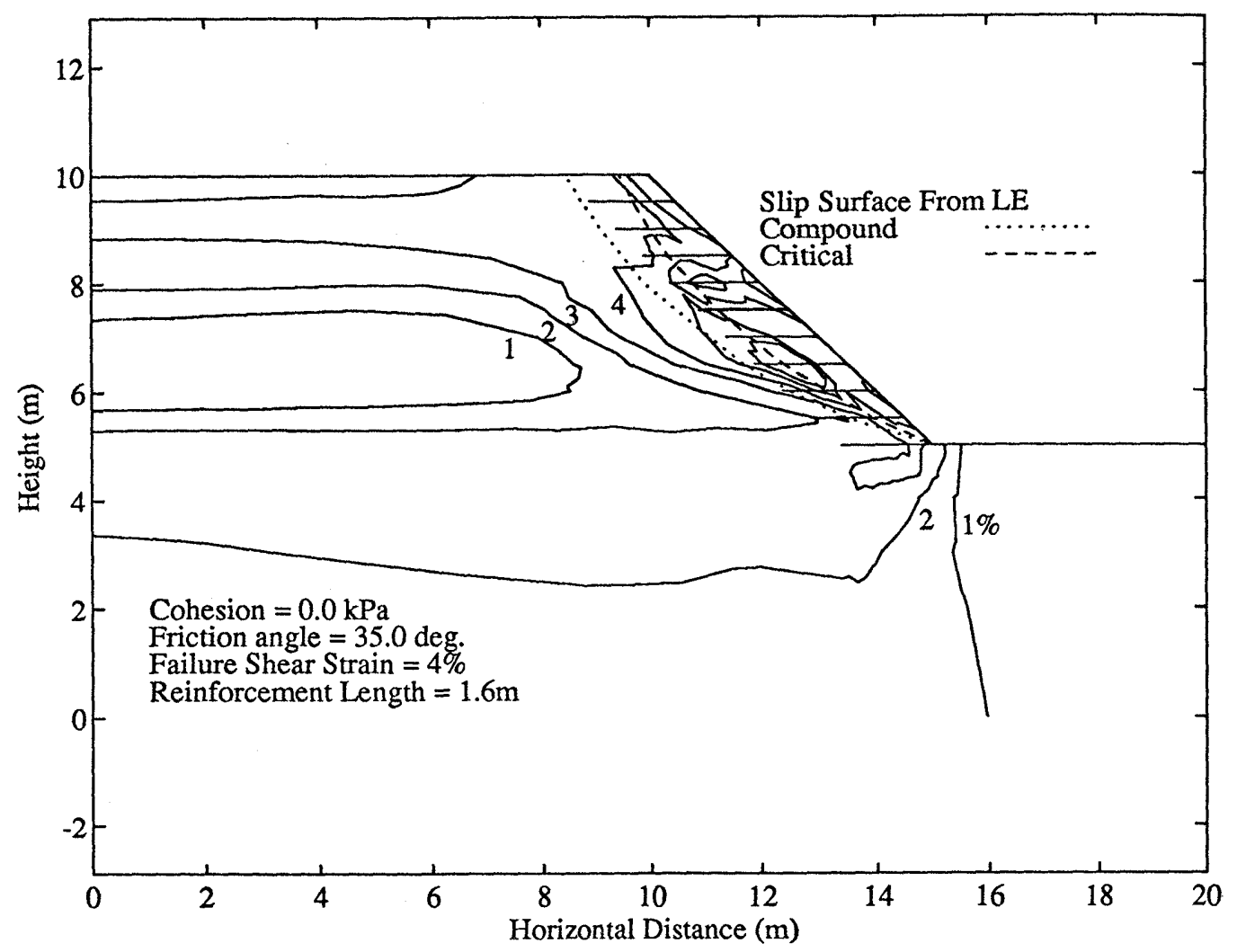

Fig. 4. Failure pattern for $45^{\circ}$ slope (dense granular backfill) 


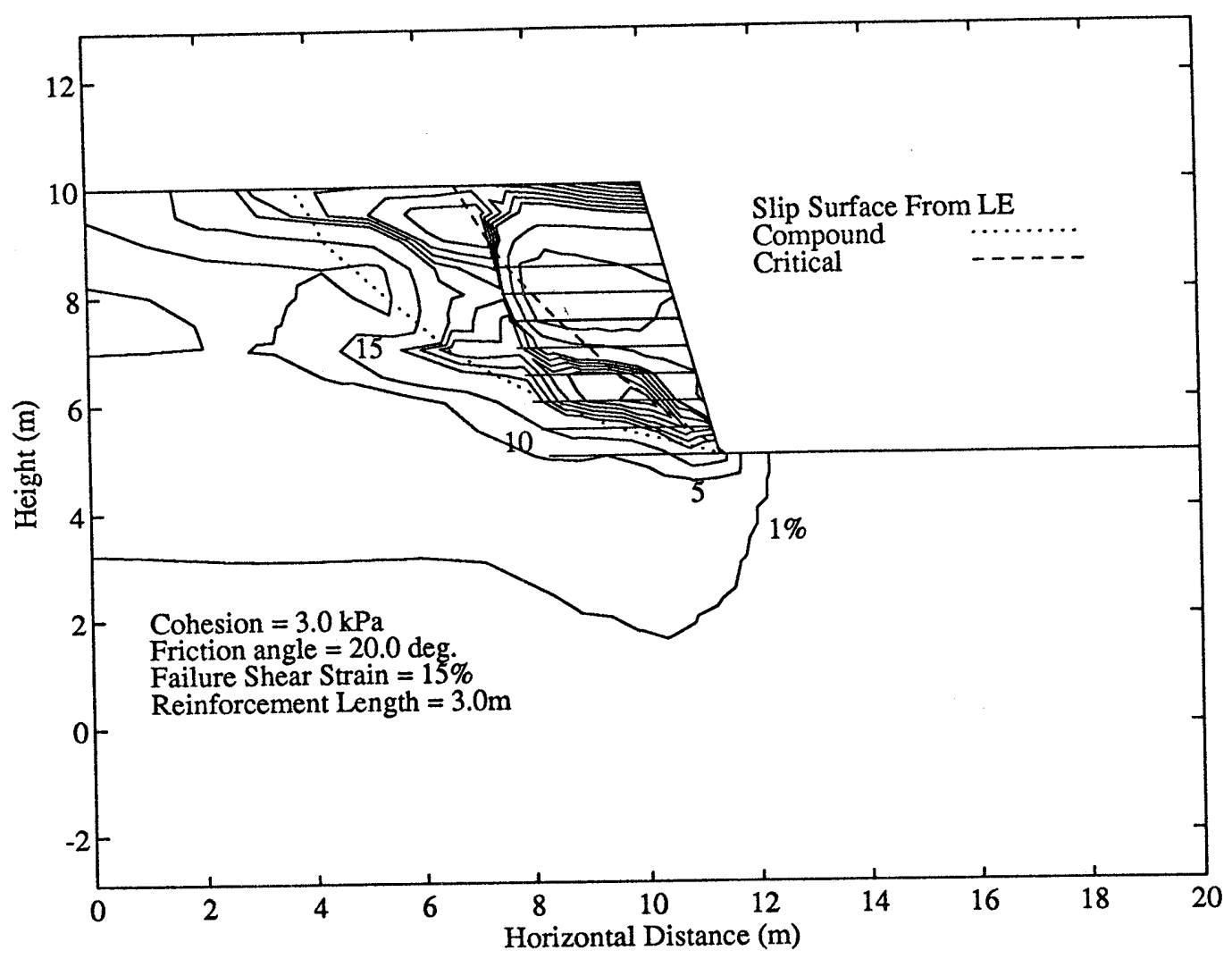

Fig. 5. Failure pattern for $7^{\circ}$ slope (loose backfil)

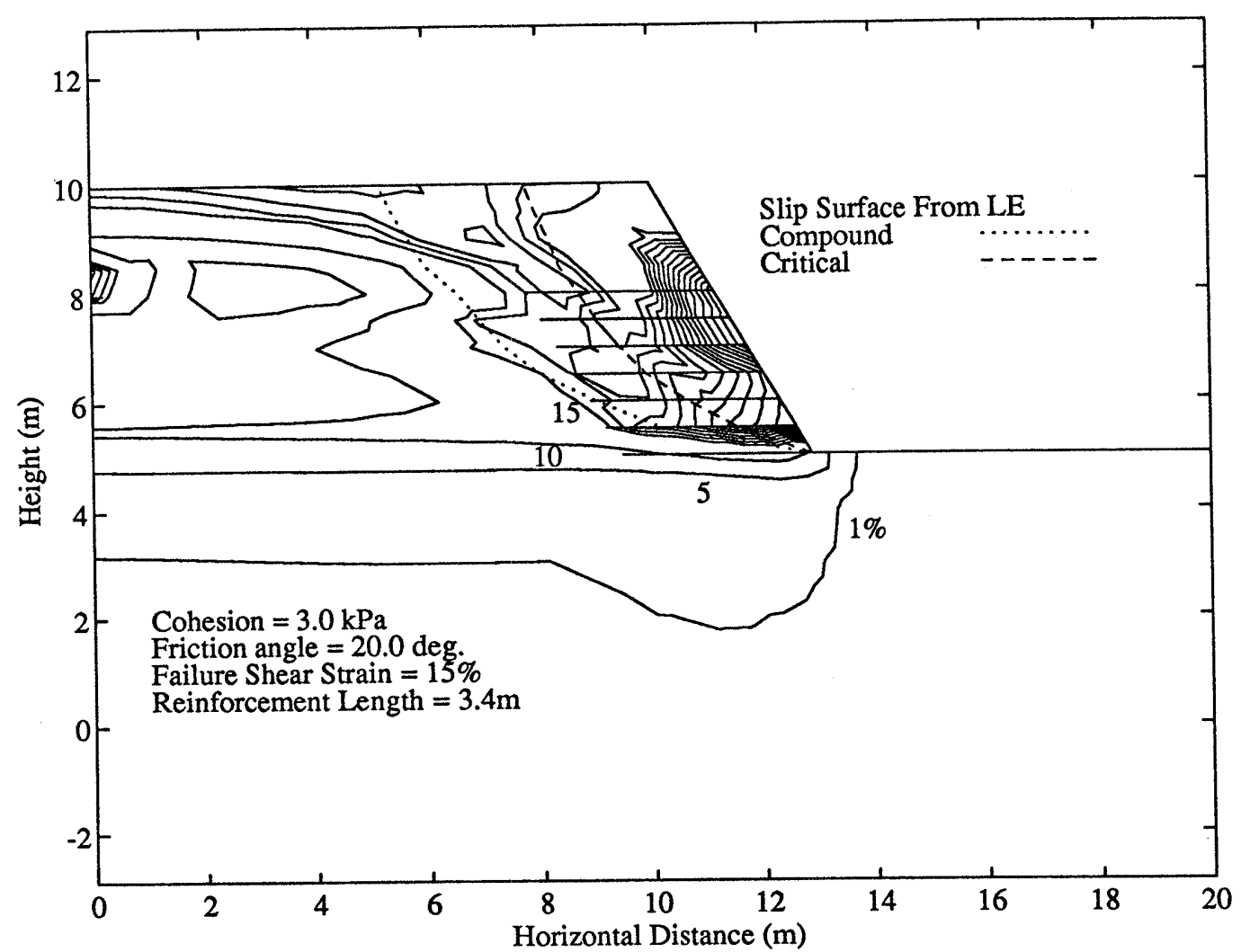

Fig. 6. Failure pattern for $60^{\circ}$ slope (loose backfill) 


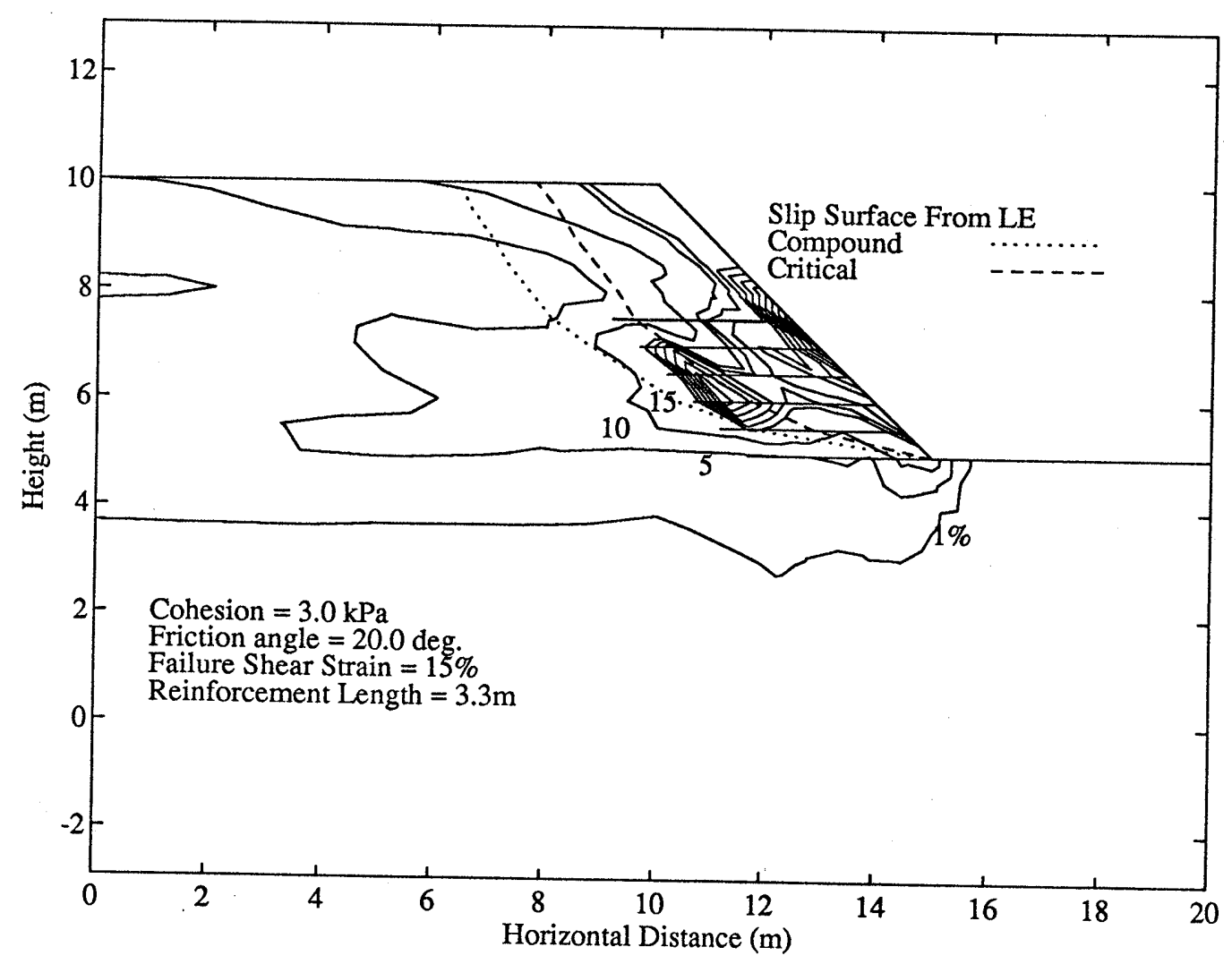

Fig. 7. Failure pattern for $45^{\circ}$ slope (loose backfill)

The summation of required tensile resistance of all reinforcement layers for both backfills obtained from $\mathrm{FE}$ are reasonably close to those obtained from LE (see Tables 3 and 4). This summation is a measure of the overall (i.e., global) equilibrium of the sliding mass, an aspect dealt with in the LE analysis. It should be pointed out that the factor of safety, $F_{s}$, in the LE analysis, was taken as one. In design, high $F_{s}$ is applied to the ultimate tensile strength of the geosynthetics (typically this $F_{s}$ is between 5 to 10 ) and therefore, the differences in the tables become less significant in practical terms. However, the

Table 3. Summation of required tensile resistance of all layers of reinforcement $(\mathrm{kN} / \mathrm{m})$ (dense granular backfiill)

\begin{tabular}{c|c|c|c}
\hline$i$ & Finite element method & STRATASLOPE & Difference \\
\hline $75^{\circ}$ & 57.7 & 41.1 & 16.6 \\
$60^{\circ}$ & 19.2 & 23.9 & 4.7 \\
$45^{\circ}$ & 14.0 & 8.9 & 5.1 \\
\hline
\end{tabular}

Table 4. Summation of required tensile resistance of all layers of reinforcement $(\mathrm{kN} / \mathrm{m})$ (loose backfill)

\begin{tabular}{c|c|c|c}
\hline$i$ & Finite element method & STRATASLOPE & Difference \\
\hline $75^{\circ}$ & 67.3 & 66.3 & 1.0 \\
$60^{\circ}$ & 35.1 & 44.6 & 9.5 \\
$45^{\circ}$ & 29.5 & 24.4 & 5.1 \\
\hline
\end{tabular}

embedment length of reinforcement is very important and is not affected by this $F_{s}$. Consequently, the comparisons shown in Figs. 2 to 7 are important.

\section{CONCLUSIONS}

Comparisons of results of analyses of geosynthetic reinforced slopes, using FE and LE, were presented. It was found that good agreement between FE and LE for a range of slope inclinations could be achieved by adjusting slightly the empirical value of $K_{0}$. Using a consistent value of $K_{0}$, the results of FE analysis agreed reasonably well with $\mathrm{LE}$ results.

\section{REFERENCES}

1) Duncan, J. M. and Chang, C. Y. (1970): "Nonlinear analysis of stress and strain in soils," Journal of the Soil Mechanics and Foundations Division, ASCE, 96 (SM5), pp. 1629-1653.

2) Leshchinsky, D. and Lambert, G. (1991): "Failure of cohesionless model slopes reinforced with flexible and extensible inclusions," Transportation Research Record, 1330, pp. 54-63.

3) Leshchinsky, D. (1992): Keynote lecture: "Issues in geosynthetic reinforced soil," Proc. of Int. Symposium on Earth Reinforcement Practice, Kyushu, (eds. Ochiai, Hayashi and Otani), Balkema, Vol. 2, pp. 871-897.

4) Matsui, T. and San, K. C. (1989): “An elastoplastic joint element with its application to reinforced slope cutting," Soils and Foundations, Vol. 29, No. 3, pp. 95-104.

5) Matsui, T. and San, K. C. (1990): "A hybrid slope stability analysis method with its application to reinforced slope cutting," Soils and Foundations, Vol. 30, No. 2, pp. 79-82. 
6) Matsui, T. and San, K. C. (1992a): "Finite element slope stability analysis by shear strength reduction technique," Soils and Foundations, Vol. 32, No. 1, pp. 27-38.

7) Matsui, T. and San, K. C. (1992b): "Availability of shear strength reduction technique," Proc. ASCE Special Conference on Stability and Performance of Slopes and Embankments-II, Berkeley, pp. 445-460.

8) Matsui, T. and San, K. C. (1992c): "Prediction of two test walls by elasto-plastic finite element analysis," Proc. of Int. Symposium on Geosynthetic Reinforced Soil Retaining Walls, Denver, pp. 259-
273.

9) Matsui, T. and San, K. C. (1993): "Reinforced slope behavior and design methods," Proc. of 1st Tokushima International Seminar on Slope Stability Engineering, Shikoku Chapter, JSSMFE, pp. 135-160.

10) San, K. C., Matsui, T. and Katsuraya, R. (1990): "Some aspects of the slop estability analysis by the shear strength reduction technique," Proc. Symposium on Geology and Slope Failure, JSSMFE, pp. 43-48 (in Japanese). 